\title{
Blood transfusion with volumetric infusion pump peripheral I.V catheter
}

\begin{abstract}
Haemovigilance is in France a system of blood transfusion surveillance procedures. Haemovigilance shows that Transfusion Associated Circulatory Overload (TACO) is a common transfusion reaction. The Incidence is probably under-evaluated because TACO is under-declared by hospitals. This has been described by FDA in 2012 and SHOT in 2013 and the ANSM report 2013. ${ }^{1}$ The aim of this work is to make the blood transfusion safer and in particular to prevent TACO by using volumetric pumps when transfusion is performed on the elderly or on patients with chronic anemia (normo-volemia), or cardiac or renal disease.
\end{abstract}

Keywords: blood transfusion, TACO, volumetric infusion pump, duration of transfusion, peripheral vein
Volume 6 Issue 4 - 2018

Jean Ginot

Regional Agency of Health Provence Alpes Cote d'Azur, France

Correspondence: Jean Ginot, Regional Haemovigilance Supervisor, in the Regional Agency of Health Provence Alpes Cote d'Azur, France, Email jean.ginot@wanadoo.fr

Received: May 18, 2018 | Published: July 27, 2018

\section{Physiopathology and prevention of TACO Physiopathology of TACO}

TACO is a pulmonary edema related to a high hydrostatic pulmonary pressure or an increased central venous pressure. In TACO, these elevations of pressure are due to circulatory overload because of transfusion. The transfusion may cause high pressure either by the positive volume balance or by an excessive flow rate. TACO occurs when the volume infused is rather high compared to the patient's weight (newborns and women are at high risk). TACO occurs at high flow rate transfusion when the patient has cardiac or renal impairment.

\section{Prevention of TACO}

Transfusion associated circulatory overload (TACO) can be prevented by reducing the volumes transfused, by avoiding transfusions when it is not necessary. A policy in France recommends transfusing only one bag a day in patients over the age of 70 , patients with cardiac or pulmonary failure, renal impairment, even if it seems not sufficient to the degree of anemia. The second unit will be postponed on next day. This has been described by Roubinian et $\mathrm{al}^{2}{ }^{2}$ TACO is also prevented by transfusing blood at a slower rate. However, in France a blood bag must be transfused in less than 2hours due to infectious risks. But it seems reasonable to prevent TACO by increasing this time up to 3 hours without worsening the infectious risk. ${ }^{1,3,4}$ Transfusing a blood bag in 3hours is very difficult as setting such a flow is not so easy. So, it appears that using a volumetric pump may be a good, or even the best, way to do so.

\section{Side effects in using a volumetric infusion pump \\ Hemolysis}

Rolf Lauber et al. ${ }^{5}$ Schumacher from the Biochemical Laboratory, Department of Anesthesiology, University Hospital, in Bern, Switzerland published in January 30, 2007 an article for CODAN entitled "In-vitro laboratory evaluation of the hemolytic effects of the finger peristaltic drive module of a CODAN ARGUS volumetric infusion pump". The authors conclude that: "the pump mechanism shows no influence on the selected markers and can therefore be safely used for transfusion of blood products such erythrocyte concentrates (packed red cells)". ${ }^{5}$

A study for Kabi Fresenius from EFS Etablissement Français du Sang (French blood bank) on August 30, 2007 shows that hemolysis is $0.1 \%$ in normal conditions of use. This result has been confirmed by 10 successive pumping. ${ }^{6}$ And this is also confirmed by Lerche et al. ${ }^{7}$

\section{Pressure of injection and risk of extra-vascular infusion}

Transfusions with pump at low flow do not seriously increase the pressure of infusion compared to drip infusion. Transfusions with pump are regularly performed in new-borns, and sometimes in adults.

\section{Risk of air embolism}

With air bubble detection either for individual air bubbles or accumulated air bubbles, and alarm of end of infusion, volumetric pumps avoid any risk of air embolism.

\section{Interest of the regulation of the flow and duration of infusion}

Using pumps is interesting in order to regulate the flow and the duration of infusion. Pumps have an automatic pressure release after occlusion, alarms for occlusion (up and downstream), air bubbles, no drops and too many drops, end of infusion. So, this is considered as high standards of security by nurses who perform blood transfusion.

\section{Practices}

\section{Practice in adults}

Transfusions are commonly performed in adult patients through a $20 \mathrm{G}$ (pink) catheter in a forearm vein, using a volumetric pump; for example, in France in the Teaching Hospital of Nîmes: gerontology medicine units and in the General Hospital of Martigues: day hospital and in the General Hospital Corte in Corsica in the medicine unit.

\section{Practice in neonatology}

In neonatology, as the volume of blood required to transfuse new-borns is very small ( 30 to $50 \mathrm{~mL}$ ), transfusion is performed with 
syringe-pumps. Blood is withdrawn through the appropriate filter with a 3 way-stopcock. 30 to $50 \mathrm{~mL}$ of blood is then injected to the patient through a $24 \mathrm{G}$ catheter. For example in Aix-en-Provence Hospital (France): Head Doctor DR Yves Rimet and in Avignon Hospital (France): Head Doctor DR Philippe Masson, use this technique.

\section{Recommendations}

Is it safe to recommend blood transfusion by pumps on peripheral veins without risk of extravascular transfusion? Pumps are made for blood transfusion as attested by manufacturers. Pumps display pressure and have audible and visual alarm, thus it seems fairly safe to do so.

\section{Blood transfusion in adults}

A blood unit is 300 to $360 \mathrm{~mL}$ : the infusion performed in 2 hours needs a flow from 150 to $180 \mathrm{~mL}$ per hour (i.e. 2.5 to $3 \mathrm{~mL} / \mathrm{min}$ ). Yet, a $20 \mathrm{G}$ (pink) catheter is made for $62 \mathrm{~mL} / \mathrm{min}$ flow, it is 20 times more than needed. Moreover, if the transfusion time is increased up to 3 hours, the flow is $2 \mathrm{~mL} / \mathrm{min}$. So we can assume that blood transfusion with a volumetric infusion pump in a forearm catheter is very safe; and it is the catheter most often used.

Nevertheless, it is also possible to use a $22 \mathrm{G}$ (blue) catheter, normally used for children $(36 \mathrm{~mL} / \mathrm{min})$, when there is no big vein available. And it is still safe, as the flow is 12 times less than the possibilities of the catheter.

Of course, an 18G (green) catheter is better as it is given for 97 to $105 \mathrm{~mL} / \mathrm{min}$ flow, so 30 times more than required for a blood transfusion.

\section{Blood transfusion in newborns}

30 to $50 \mathrm{ml}$ of blood are injected to patients through a $24 \mathrm{G}$ (yellow) catheter in a forearm vein, therefore, there is a 15 to $25 \mathrm{~mL}$ per hour flow to infuse it in 2 hours. $24 \mathrm{G}$ catheters are indicated for a maximum rate of $24 \mathrm{~mL}$ per min flow, so they are used at a rate of 30 to 60 times less as indicated.

\section{Conclusion}

A volumetric infusion pump gives the right duration of a transfusion. So its use prevents risks of TACO occurrence particularly in patients with cardiac or pulmonary failure, renal impairment, in patients over the age of 70 , and also in newborns as described by Alam et al., ${ }^{4}$ and by Whyte et al. ${ }^{8}$ Using a volumetric infusion pump makes a constant flow, and gives occlusion and end of bag signals. These signals, along with the constant flow, seem to provide a high standard of safety for nurses in charge of transfusion.

Fear of an extra-vascular transfusion, particularly in peripheral vein, is avoided:

A. As attested in practice, transfusion is currently performed in adults, even in pediatrics.
B. As flows requested for a blood transfusion are 20 to 30 times less than the possibility of catheters ( $24 \mathrm{G}$ for children, $20 \mathrm{G}$ or $18 \mathrm{G}$ for adults)

C. As pumps display pressure and have audible and visual alarm.

D. As pumps are made for blood transfusion

The problems are:

a) The extra cost, since the tubing for a pump is a little more expensive than a tubing for free dripping on a drip stand.

b) The setting time of the transfusion is a little bit longer than the transfusion by declivity on drip stand.

In spite of the two minor problems, it is very helpful to transfuse with a peristaltic infusion pump and it seems very safe to transfuse in a peripheral forearm vein. It is not necessary to set a central line to use infusion pumps to transfuse.

\section{Acknowledgements}

None.

\section{Conflict of interest}

The author reports no conflicts of interest in this work.

\section{References}

1. ANSM. Edèmes aigus de surcharge post-transfusionnels. Rapport septembre. 2013.

2. Roubinian N, Murphy E. Transfusion-associated circulatory overload (TACO), prevention, management, and patient outcomes. International Journal of Clinical Transfusion medicine. 2015;2015(3):17-28.

3. Huy Phu. Transfusion associated circulatory overload (TACO). Transfusion medicine and hemostasis. 2011.

4. Alam A, Lin Y, Lima A, et al. The prevention of transfusion-associated circulatory overload. Transfus Med Rev. 2013;27(2):105-112.

5. Rolf Lauber, Sibylle Rohrbach, Peter M. In-vitro laboratory evaluation of the hemolytic effects of the finger peristaltic drive module of a CODAN ARGUS volumetric infusion pump. Schumacher Biochemical Laboratory, Department of Anesthesiology, University Hospital, Bern, Australia; p. 1-2.

6. Stéphane Begue. Volumat Agilia peristaltic pump for IV perfusion of RBC. Head Quality EFS évaluation of potential déléterious effect of Kabi Frésénius, Ireland, p. 1-2.

7. Lercche D, Merk A. In vitro evaluation of hemolytic effects with use of infusion pumps with finger peristaltic action of blood pumping. Anesthesiol Intensivmed Notfallmed Schmertzther. 1996;31(9):568-572.

8. Robin K Whyte, Ann L Jefferies. Société canadienne de pédiatrie, Comité d'étude du foetus et du nouveau-né. Paediatr Child Health. 2014;19(4):218-222. 